\title{
A proteção da infância no Brasil: uma visão crítica das relações intergeracionais
}

\section{Childhood protection in Brazil: a critical perspective on intergenerational relations}

\section{La protección de la niñez en Brasil: una visión crítica de las relaciones intergeneracionales}

\author{
Suzana Santos Libardi* \\ Universidade Federal do Rio de J aneiro - UFRJ, Rio de Janeiro, Rio de Janeiro, Brasil \\ Lucia Rabello de Castro** \\ Universidade Federal do Rio de J aneiro - UFRJ, Rio de Janeiro, Rio de Janeiro, Brasil
}

\begin{abstract}
RESUMO
Este trabalho apresenta uma discussão, historicamente embasada, de como se configurou a noção de proteção da infância no Brasil. Ainda, apresentamos a proteção em interface com as relações intergeracionais, entre adultos e crianças, de modo a responder à pergunta: como a ideia de proteção da infância modela as relações intergeracionais entre adultos e crianças no contemporâneo? Como elementos desta discussão, discutimos o viés classista e racializado constitutivo da emergência da noção de proteção no país com dois principais desdobramentos: a dificuldade de que ela possa orientar no presente práticas de cuidado às crianças compatíveis com a noção de criança como sujeito de direitos; a dificuldade para se efetivar a infância como uma categoria geracional universal compreendendo todas as crianças nesta unidade.
\end{abstract}

Palavras-chave: proteção, infância, relações intergeracionais, geração.

\begin{abstract}
This work aims at presenting a historically-based discussion of the notion of childhood protection in Brazil. Furthermore, the notion of protection is presented in the scope of intergenerational relations, between adults and children, in order to answer the question: How does the idea of childhood protection shape the intergenerational relations between adults and children in the contemporary Brazil? As elements of this discussion, we present the racialized and class-oriented constitutive bias of the emergence of the notion of protection in the country, producing two main consequences: its difficulty to guide, nowadays, practices of child care which are compatible with the notion of the child as a subject of rights; its difficulty to consolidate childhood as a universal generational category including all children in this unity.
\end{abstract}

Keywords: protection, childhood, intergenerational relations, generation. 


\begin{abstract}
RESUMEN
Este trabajo presenta una discusión, históricamente con base de cómo se configuró la noción de protección de la niñez en Brasil. Además, presentamos la protección en interfase con las relaciones intergeneracionales, entre adultos y niños, de modo a contestar a la pregunta: ¿Cómo la idea de protección de la niñez modela las relaciones intergeneracionales entre adultos y niños en el contemporáneo? Como elementos de discusión, planteamos la huella clasista e interracial constitutiva de emergencia de la noción de protección en el país con dos principales despliegues: la dificultad de que esta pueda orientar en el presente prácticas de cuidado a los niños compatibles con la noción de niño como sujeto de derechos; la dificultad para efectuar la niñez como una categoría generacional universal comprendiendo todos los niños en esta unidad.
\end{abstract}

Palabras clave: protección, niñez, relaciones intergeneracionales, generación.

\title{
1. I ntrodução
}

Nos estudos da infância considera-se que a construção da infância decorre de processo social e histórico (Qvortrup, 2011a, 2011b) e que, no mundo ocidental, sua construção se alimentou das teorias do desenvolvimento elaboradas na Modernidade (Gillis, 2011; Smolka, 2002), entre outros fatores. As noções de desenvolvimento e progresso difundidas pelo projeto moderno influenciaram a forma como a infância moderna foi sendo construída, estudada (Castro, 2012; KjØrholt, 2013), bem como padronizada (Heywood, 2001). O campo da psicologia do desenvolvimento, como configurado hoje, por exemplo, foi um dos responsáveis por produzir estudos pioneiros sobre desenvolvimento (ou maturação) infantil e teceu a criança como imatura, entre outros aspectos (Burman, 2008), produzindo uma imagem da infância como fase da vida na qual o sujeito deve ser especialmente cuidado e protegido. Esta concepção ocidental (Stearns, 2006), ou melhor, europeia, da infância produziu impactos na construção da infância no Brasil e no mundo, na experiência das crianças e, mais ainda, impactou na maneira como esse grupo geracional foi sendo tratado ao longo de nossa história por iniciativas públicas e privadas.

Partindo desses pressupostos, examinamos no presente trabalho um dos aspectos envolvidos no trato da infância no Brasil, a saber: sua proteção. A análise sobre o tema foi feita adotando uma perspectiva geracional (Alanen, 2011; Alanen \& Mayall, 2001), que percebe adultos e crianças como sujeitos de grupos de geração (Freixa \& Leccardi, 2010; Qvortrup, 2011a; Weller \& Motta, 2010). Isso significa que tomamos a atuação desses indivíduos considerando sua dimensão coletiva relacional, ou seja, considerando que suas possibilidades de ação na estrutura da sociedade (Weller, 2010) 
provêm da posição de interdependência entre os distintos grupos geracionais. Sendo a proteção da infância o objeto deste trabalho, buscamos refletir sobre como as relações entre a geração dos adultos e a das crianças são impactadas pela ideia de proteção na realidade brasileira. A pergunta que buscamos responder neste trabalho foi: Como a ideia de proteção da infância modela as relações intergeracionais entre adultos e crianças no contemporâneo?

Neste trabalho identificamos elementos pertinentes para pensar essa questão. Inicialmente apresentamos a ideia de proteção na história social da infância no Brasil, com um resgate histórico de como ela foi se configurando no país, tendo em vista as relações de reciprocidade intergeracional entre adultos e crianças. Depois, referenciamos o debate dentro da legislação internacional sobre os direitos da criança e as mobilizações no Brasil - a luta dos movimentos sociais no contexto da redemocratização - que culminaram com a criação do Estatuto da Criança e do Adolescente (ECA). Finalizamos levantando alguns problemas e desafios que resultam da condição de se pensar a proteção da infância sob o enfoque geracional.

\section{A I deia De Proteção Na História Social Da Infância No Brasil}

Nesta seção percorremos brevemente a história social da infância no Brasil (Freitas, 2003), identificando como as ações de proteção deram corpo ao discurso de que toda criança deve ser protegida - apesar de na prática a proteção não se concretizar dessa maneira. Para isso, nos remetemos à história da assistência à criança no Brasil que, segundo Kramer (1982), pode ser dividida em duas grandes fases, para fins didáticos.

A primeira fase abarca período desde a colonização até a década de 1930 e apresenta subdivisões internas (Kramer, 1982). A segunda fase compreende as décadas de 1930 a 1980, quando da publicação da análise da autora (Kramer, 1982). Pelo longo período histórico abarcado na análise, contamos também com a contribuição de outros autores (Faleiros, 2011; Freitas, 2003; Goés \& Florentino, 2013; Kuhlmann Jr., 2010; Lajolo, 2003; Mauad, 2013; Priore, 2013). Adicionamos uma fase a mais para essa retomada da história da assistência à infância (discutida na próxima seção deste trabalho), que parte dos anos de 1980, engloba a criação do Estatuto da Criança e do Adolescente (ECA) do Brasil e pensa a realidade dos direitos das crianças e de sua proteção no contemporâneo. 


\section{A Emergência Da Proteção Social No Brasil: Quem Cuida Das I nfâncias Brasileiras?}

A primeira fase da história do atendimento à criança no Brasil, fase pré-1930 (Kramer, 1982), se subdivide em três períodos: 1ํ) iniciada com a colonização portuguesa e se estende até 1874; 2ㅇ) de 1874 até 1899; 3ㅇ) de 1899 até 1930.

A primeira subfase vai do começo da colonização do Brasil até o século XIX, quando o país passa por mudanças profundas que marcam os anos de 1800: a abertura dos portos e do mercado, a vinda da Família Real Portuguesa, depois a Independência, instalação do Brasil-Império, até finalmente alcançarmos a promulgação da Lei do Ventre Livre em 1871. Ao longo desse período, esses e tantos outros acontecimentos se desenrolaram tendo suporte do regime escravocrata. Esta estrutura afetou a vida das crianças e a produção da infância no nosso país.

No que tange à infância, o caráter familiar da escravidão brasileira (Pinheiro, 2006) fez com que as crianças filhas de escravos vivessem em meio à crianças brancas. Segundo Mauad (2013), entre as crianças brancas diferenciava-se a vida das crianças de elite durante - Império. Para essa infância havia vestuário diferenciado dos adultos, brinquedos começavam a ser fabricados, fábulas publicadas em livros infantis e a puericultura era área especializada da medicina que se ocupava do desenvolvimento fisiológico da criança pequena. Segundo a autora, a existência de cuidados direcionados exclusivamente à criança de elite confirma o entendimento, ainda que incipiente, da infância como fase peculiar da vida, pelo menos entre a elite oitocentista do Brasil.

A convivência entre crianças negras e brancas, escravizadas e livres, contribuiu para que aquelas primeiras não pudessem usufruir de um modo de ser criança que era facultado às segundas. Um exemplo disso é o tratamento gentil ou carinhoso que por vezes adultos destinavam às crianças, especialmente quando ainda bebês. No caso das crianças filhas de escravos, tais mimos lhes eram destinados pelos senhores e senhoras com frequente menção à sua condição de submissão e objetificação: usados muitas vezes para animar os adultos ou divertir crianças ricas (Faleiros, 2011; Priore, 2013).

Os filhos de escravos negros no Brasil circulavam amplamente pela propriedade do senhor, e chegavam a ser próximos dos filhos da nobreza, mas por volta dos sete anos já eram inseridos no trabalho (Faleiros, 2011; Goés \& Florentino, 2013). Esse trato era completamente distinto da tutela destinada às crianças brancas - que por vezes viviam sob moratória até maior idade para estudar. Fica evidente que o protótipo de infância gestado na modernidade europeia não se aplicava para crianças escravizadas ou filhas de adultos escravizados. Este grupo, tão logo era enxergado como mão 
de obra a ser explorada, não era enquadrado como criança. Pode-se dizer que no Brasil nossa história de colonização e dominação construiu o pertencimento das crianças de forma diferente. Além disso, no que tange ao tipo de relação intergeracional direcionado às crianças, crianças escravizadas eram colocadas muito cedo numa posição de exploração perante adultos brancos; similar a dos adultos negros também escravizados. Ao contrário, crianças brancas de elite viviam durante sua infância relações intergeracionais que lhe proviam algo mais próximo do que hoje compreendemos por tutela e proteção, visto que os adultos já estavam ali investindo na sua instrução, formação e cuidado.

Considerando que a assistência às crianças pode prover formas diferentes de proteção, cabe resgatar o surgimento dos serviços destinados às crianças, já que eles concretizaram a noção da proteção sob a forma de diferentes práticas de assistência. As primeiras ações de atendimento às crianças no Brasil enfrentaram o problema do abandono de crianças. Desde o século XVII no Brasil se observa crianças abandonadas ainda muito pequenas, bebês, em praças, praias, à porta de residências ou Igrejas (Faleiros, 2011). A situação de miséria ou pobreza não justificava todos os casos de abandono de criança nessa fase da história brasileira. A maioria das crianças entregues a doação ou abandonadas era mestiça (Faleiros, 2011), o que demonstra que o motivo provável do abandono era o desejo de não assumir a ilegitimidade da prole derivada da união entre pessoas livres e escravas.

Essa realidade influenciou a produção da infância no Brasil ao gerar a percepção de que nem todas as crianças estariam enquadradas no âmbito do grupo geracional que é a infância, e daí, serem por si mesmos objetos de valor. A ideia de infância no Brasil se demarca pelas condições de desigualdade da sociedade e se cola a uma população específica de crianças. Fazem parte da infância as crianças valorizadas como objetos de investimento adulto, enquanto outras são objetos a serem explorados como mão de obra ou descartáveis.

A primeira iniciativa de atendimento às crianças no Brasil foi destinada para aquelas que haviam sido abandonadas. Efetivou-se aqui o serviço que já existia em Lisboa: a Roda dos Expostos, instituição largamente estudada por pesquisadores brasileiros da história, da educação, da assistência social, entre outros (Leite, 1991; Rizzini \& Rizzini, 2004). O atendimento na Roda não se restringia à acolhida imediata das crianças desvalidas, abandonadas, mas incluía todo um sistema de atenção destinado às crianças durante todo o tempo que podiam ficar sob guarda da Santa Casa (Faleiros, 2011). A proteção que se dizia oferecer era em um sentido mais imediato, uma proteção material que visava dar mínimas condições de sobrevivência para a criança e era defendida pela medicina e pelos pediatras brasileiros à época: abrigando-a, 
alimentando-a, asseando-a. A criança era objeto de proteção social (Pinheiro, 2006) e a noção de proteção propagada nesse contexto objetivava minimamente preservar a vida - por mais que fossem conhecidos os altos índices de mortalidade infantil dentro da instituição, demonstrando que na realidade o objetivo de proteção da vida da criança não era satisfatoriamente atingido - . Tal proteção era vista como ato de caridade (Passetti, 2013), uma ação de generosidade ou benevolência de grupos abastados que não alterava a estrutura racializada das mentalidades. Assim, a Roda se concretiza como medida de enclausuramento e custódia da criança rejeitada no Brasil-Colônia e Império.

Assim, as práticas de atendimento à infância visavam dar algum provimento aquelas crianças desvalidas, desvelando um sentido de proteção da infância articulada à sua origem social e raça. Não se tratava apenas de que a criança tivesse pouca idade, mas também de que estivesse em determinada posição social e racial, para ser considerada como 'objeto da proteção do adulto'.

A segunda subfase mencionada anteriormente, de 1874 até 1899, compreende período de formalização da Lei Áurea e últimos anos do Brasil-Império. Nesse período, aumenta a quantidade de serviços que atendem a criança, se apresentando como mecanismos de custódia para as crianças pobres, não apenas as órfãs. Destaca-se a expansão da Roda por várias cidades do país (Faleiros, 2011) e a criação de novas instituições - o Azilo de Meninos Desvalidos, os Institutos de Menores Artífices e o 1ํ Jardim de Infância do Brasil Menezes Vieira, por exemplo (Kramer, 1982). Esses serviços tinham objetivo de combater a mortalidade infantil e eram projetos de grupos particulares, especialmente médicos, com caráter higienista e atuação preconceituosa (Kuhlmann Jr., 2010) diferenciando o trato com as crianças a partir de sua cor.

A assistência oferecida se resumia a prover abrigo e em poucos casos os meninos aprendiam algum ofício, permanecendo o assistencialismo marcante da atuação. Ações de preservação da vida, abrigamento, alimentação e higiene eram executadas por instituições privadas de cunho filantrópico direcionadas apenas às crianças pobres e/ou abandonadas. Desse modo, esta ideia de proteção está entranhada pelo sentido caritativo limitado à custódia da criança e, ulteriormente, ao seu aproveitamento como mão de obra servil.

A 'proteção social' da criança pobre ofertada pós Lei Áurea se remete então ao trato que a elite oitocentista brasileira promovia para a população negra livre sob a justificativa da filantropia, mas claramente influenciada pelos setores dominantes da época e com intenções de controle sobre essa população. A criança pobre era objeto de assistência caridosa, enquanto a criança das elites era objeto de investimento, educação, mimo, buscando corresponder ao ideal de infância moderna. As demandas geracionais que esses dois 
grupos colocavam aos adultos diferiam radicalmente: enquanto o primeiro demandava a exibição da generosidade altruísta do adulto, e provavelmente mobilizava seus sentimentos de pena e compaixão, o outro implicava o adulto em uma relação de dever - a ação educadora como a norma que volvia o mais velho em direção aos mais novos, mobilizando neles o afeto e o orgulho narcísico.

A terceira subfase da história do atendimento à criança no Brasil compreende período de 1899 a 1930 (Kramer, 1982; Kuhlmann J r., 2010) e corresponde aos primeiríssimos anos de República. Esse foi período da expansão do conhecimento médico-higienista no país (Kuhlmann Jr., 2010), responsável pela diminuição significativa da mortalidade infantil, e também do avanço do atendimento de crianças nas instituições médicas, escolares e de assistência.

Dentro desta terceira subfase, mais precisamente na virada do século XIX para o XX, são criadas novas instituições e leis para o atendimento à criança. Algumas creches, jardins de infância, publicações em jornais e realização de congressos. Considerando o objetivo do presente trabalho, destacamos entre as iniciativas o IPAI (Instituto de Proteção e Assistência à Infância do Brasil). Criado pela iniciativa privada em 1899, e tendo se estendido por todo território nacional (Kramer, 1982; Kuhlmann Jr., 2010), o IPAI reunia pessoas dispostas a financiar benfeitorias e profissionais que trabalhavam com a criança, como médicos da puericultura, por exemplo. O objetivo do IPAI era:

atender os menores de oito anos; elaborar leis que regulassem a vida e a saúde dos recém-nascidos; regulamentar o serviço das amas de leite, velar pelos menores trabalhadores e criminosos; atender às crianças pobres, doentes, defeituosas, maltratadas e moralmente abandonas; criar maternidades, creches e jardins de infância. (Kramer, 1982, p. 54)

A partir daí nos parece claro que o IPAI intervém sob a criança, mas atua sobretudo contra a pobreza. Afinal, a criança que se julgava "precisar" de assistência e, daí, algum tipo de proteção, é a criança dita desvalida, não outra. Cabe ressaltar também que a figura da criança é evocada quando se trata de alguém que sofre de alguma forma de abandono ou mazela. Porém, quando a criança pobre escapa dessa imagem indefesa, trabalhando ou infringindo leis por exemplo, passa a ser vista como o menor. Desse modo, a criança objeto de intervenção do IPAI oscilava entre a imagem da criança inocente que foi vitimada e a imagem do menor, o pequeno marginal. Destacamos que naquele contexto histórico o Estado ainda não era visto como responsável por prover quaisquer atenções para crianças pobres, de modo que esse campo era hegemonizado pela filantropia dos setores mais ricos da sociedade e suas forças higienista, médica 
e religiosa (Kuhlmann J r., 2010) - sendo também uma forma desses setores definirem os rumos da criança pobre no Brasil. À medida que a república brasileira foi se consolidando, estes setores da sociedade passaram a pressionar governantes para que se ocupassem do problema da criança desprotegida (Kramer, 1982).

Com o objetivo de responsabilizar o Estado, o Departamento da Criança no Brasil, criado pelo IPAI em 1922, realizou no Rio de Janeiro o I Congresso Brasileiro de Proteção à Infância (Kramer, 1982). O evento reuniu pessoas de governo, de iniciativas privadas de atendimento e especialistas de várias áreas do atendimento da criança com objetivo de "tratar de todos os assuntos que direta ou indiretamente, se refiram à criança, tanto do ponto de vista social, médico, pedagógico e higiênico" (Regulamento do I Congresso como citado em Kramer, 1982, p. 55), destacando-se como momento onde governantes brasileiros começam a ser pressionados a organizar a assistência à infância. O I Congresso aparece como acontecimento relevante para se pensar a proteção porque traz o Estado como agente que passa também a ser responsabilizado pela promoção do atendimento à criança e, com isso, da proteção que se julgava que ela tinha que receber.

O sentido das ações de proteção, por consequência, também mudou, sendo visto aos olhos republicanos como forma de ajudar o país a se tornar um país "desenvolvido" (Castro, 2012). O cuidado das gerações pobres mais novas intenciona continuidade de um projeto de desenvolvimento para nação (Kuhlmann J r., 2010). Aqui a criança e também o adolescente são tidos majoritariamente como objetos de controle e disciplinamento social (Pinheiro, 2006), visto a abundante situação de pobreza da população negra após a recente Abolição. A inserção de jovens pobres nos postos de trabalho abertos pela expansão da indústria - e a inserção de crianças pobres nas creches e escolas - colaboraria para o desenvolvimento da nação e impediria de se tornarem 'ociosos', 'desocupados', 'despreparados' (Passetti, 2013).

$\mathrm{O}$ atendimento à criança assumido pelo Estado manteve o caráter assistencial de abrigamento e custódia. As ações de filantropia promovidas exclusivamente por setores privados da sociedade civil visavam preservar a vida e guardar socialmente a criança abandonada ou pobre, executando um papel que era esperado das famílias. A partir dos anos de 1920, ações incipientes do Estado mostram a assunção de obrigações que este passa a assumir para com as crianças desvalidas: o Estado como substituto da ação parental e das famílias quando estas faltam. A ação estatal toma simplesmente o lugar da ação caridosa das elites - até porque essas constituem o Estado neste momento inicial da república brasileira. $O$ que queremos assinalar é que a passagem para o Estado do provimento da assistência à criança pobre não está articulada em 
uma outra acomodação de interesses sociais, mas permanece fundado na guarda e no controle das crianças pobres. Assim, a assistência à criança pobre pelo Estado não se amparou nos ideais de equidade e justiça em relação a todas as crianças as quais seria dever do Estado oferecer a provisão necessária em educação e saúde. Neste sentido, não parece haver mudança na estrutura das mentalidades que ainda discriminam as crianças e atribuem a elas valores distintos conforme sua classe social e raça. A criança pobre passa a ser gradualmente ônus do Estado que, elitista e autoritário, oferece assistência precária àquelas crianças sem aportes familiares. Para as crianças das elites, as famílias continuarão como precipuamente responsáveis pelo seu bem-estar e educação (Castro, 2013).

\section{Proteção Integral Da Infância A Serviço Da 'Modernização’ E Do 'Desenvolvimento'}

Um segundo grande período na história do atendimento à criança no Brasil se estende de 1930 (Kramer, 1982) a 1980 quando o Estado passa gradualmente a centralizar e organizar os serviços para a infância cuja representação ganha contornos mais universais. Os serviços destinados à criança pobre aumentam enormemente em quantidade e não se limitam mais ao âmbito da assistência social, mas também ao da educação. O país encontra-se numa fase de crescimento econômico e industrialização, difundindo a imagem de se tornar moderno e grande. A criança passa a ser vista como "o futuro da nação". Nesse sentido, cuidar da criança pobre significou apostar na robustez de um projeto de sociedade moderna. Nesse período o Estado divide, inicialmente, os custos dos serviços com a iniciativa particular - associações religiosas, organizações médicas, de educadores, ou leigos - e centraliza direção e controle do atendimento (Kramer, 1982).

Dentre as ações, foram instaurados novos órgãos: lactários, gotas de leite, consultórios para lactentes, policlínicas infantis, jardins de infância, escolas maternais. Havia também campanhas para aleitamento materno e foi realizado o II Congresso de Proteção à Infância, em 1933 - num cenário político bem diferente do I Congresso. A década de 1940 começa com a criação do Departamento Nacional da Criança, ligado ao Ministério da Saúde, com objetivo de coordenar e fiscalizar atividades nacionais públicas ou privadas de proteção à infância, maternidade e adolescência. Em 1942 criou-se a LBA (Legião Brasileira de Assistência) com apoio de setores da indústria e comércio (Kramer, 1982), que objetivava reunir pessoas e instituições públicas ou privadas para prover serviços de assistência que protegessem também a maternidade e a infância (Kramer, 1982). Ao mesmo tempo, cria-se no Ministério da 
Justiça o SAM (Serviço de Atendimento ao Menor), depois substituído pela FUNABEM (Fundação Nacional para o Bem Estar do Menor) e suas instituições estaduais, as FEBEMs (Fundação Estadual para o Bem Estar do Menor), que atendiam crianças abandonadas e também "menores delinquentes". Em 1974 a LBA, já transformada em Fundação, começa a executar o grandioso Projeto Casulo, que com financiamento público objetivava prestar assistência ao menor de seis anos para prevenir a "marginalidade", abrindo espaço para mulheres se inserirem no mercado de trabalho, pois podiam deixar seus filhos nas unidades municipais e estaduais que executavam o projeto por todo território nacional (Kramer, 1982).

Percebe-se então que o atendimento às crianças ganha contornos em que se procura discriminar dentre as crianças pobres aquelas que são consideradas como necessitando de "cuidados", enquanto as outras, as "delinquentes", são separadas para assistência específica. Isso diz respeito à relativa disjunção que se aplicou à associação entre pobreza e criminalidade, uma vez que agora a criança pobre passaria a ser atendida preferencialmente por serviços distintos dos reservados ao menor. Em consequência, a criança pobre pôde ser considerada como objeto de proteção, ainda que a concretização destas práticas de proteção ficasse efetivamente a desejar, e o menor não fosse visto como necessitando de proteção.

Em relação às crianças pobres, a proteção era promovida por meio da higiene e assistência social, permanecendo seu caráter médicohigienista. A tônica do atendimento era médica. Em relação aos menores, a ideia de proteção não se concretizava, pois eram vistos como bandidos a quem se destinava punição - sendo as unidades estaduais da FEBEM conhecidas amplamente pelos maus-tratos e castigos. As crianças "delinquentes" eram desde aí objetos de repressão social (Pinheiro, 2006) recolhidas a instituições 'reformatórias'. Assim, a ideia de proteção não adentrou até hoje a vida dessas crianças.

\section{A Proteção Da Infância E Os Direitos Da Criança: A Retórica Internacional E As Mobilizações No Brasil}

A segunda metade do século $X X$ no Brasil foi marcada por transformações sociais e políticas, ocorridas principalmente a partir de 1968 com o acirramento da ditadura militar e a atuação dos movimentos de resistência e de luta pela democracia. No que tange à geração da infância, o final da década de 1970 e a década de 1980 foram marcados pela publicização das más condições de vida de grande parte das crianças e adolescentes que viviam em situação de pobreza extrema no Brasil. Neste período a questão da criança e do adolescente pobres atingiu repercussão pública de problemática social 
(Pinheiro, 2006), aparecendo por via da atuação dos movimentos de defesa dos direitos da criança. Trata-se, portanto, de um período de luta por reconhecimento legal, no Brasil, da criança como sujeito social, detentora de direitos e que deve ser priorizada nas políticas de Estado.

A referência em vigor em termos de legislação sobre a criança marginalizada era o Código de Menores de 1979 - sendo que o Brasil já havia sido signatário do primeiro Código de Menores, de 1927 que refletia sua noção de 'proteção assistencialista-correcional' (Arantes, 2009, p. 447) e a Doutrina da Situação Irregular como seu escopo jurídico. A política que regulava o atendimento à infância era a Política Nacional do Bem Estar do Menor e, portanto, restrita a esse grupo de crianças, sendo centralizada pela FUNABEM e FEBEMs e se concretizando via encarceramento. Até aqui as práticas institucionais de repressão e violência refletiam a ideia da proteção da sociedade em relação ao 'menor' marginal, mais do que propriamente a de proteção do 'menor' (Rizzini \& Rizzini, 2004).

No que tange ao atendimento das crianças não marginalizadas, muitos dos serviços executavam práticas de assistência e refletiam trato da criança como objeto de intervenção, sendo majoritariamente normatizadas por entidades governamentais e executadas pelo governo e/ou pela sociedade civil, como por exemplo: a Igreja Católica com a Pastoral da Criança, criada em 1983, que oferecia serviço de atenção básica à saúde do bebê e da criança até 6 anos. As práticas de assistência seriam aquelas que já ocorriam previamente, em outros períodos da nossa história.

Por outro lado, na década de 1970 foram se intensificando práticas que priorizavam a defesa de direitos e não ofereciam, em sua maioria, serviços assistenciais. Esta atuação tentava refletir a concepção da criança como sujeito de direitos e se buscava garantir por via da militância política e pela oferta de ações educativas o empoderamento das crianças: estimulando-as a se responsabilizar pela sua própria educação, mesmo que em contextos adversos, como era o caso das crianças em situação de rua (Pinheiro, 2006). Tais práticas foram inicialmente predominantemente encampadas por organizações e grupos da sociedade civil, a saber: a RPV (República do Pequeno Vendedor) criada em 1978; o MDM (Movimento de Defesa do Menor) criado em 1979; a Igreja Católica, via Pastoral do Menor, criada em 1978 e voltada para a defesa da criança e do adolescente marginalizados, e a Campanha da Fraternidade de 1987, que tinha como tema 0 acolhimento à criança marginalizada (Pinheiro, 2006); o MNMMR (Movimento Nacional de Meninos e Meninas de Rua) criado em 1985; o Fórum DCA (Fórum Nacional Permanente de Entidades Não-Governamentais de Defesa dos Direitos da Criança e do Adolescente) fundado em 1988. Já na década de 1980 as práticas de defesa de direitos receberam mais suporte e 
reconhecimento governamentais via, por exemplo: o PAAMR (Projeto Alternativas de Atendimento a Meninos de Rua), criado em 1984 pela parceria entre FUNABEM e UNICEF (Fundo nas Nações Unidas para a Infância) (Pinheiro, 2006); a FNDDC (Frente Nacional de Defesa dos Direitos da Criança), fundada em 1985; e a campanha Criança e Constituinte, do Ministério da Educação, iniciada em 1986.

A luta dos direitos da criança foi encampada por pessoas e/ou instituições, governamentais ou não, que trabalhavam com os 'menores' em espaços de encarceramento, comunitários e/ou em ações educativas de rua. Tal origem institucional da luta pelos direitos da criança no país revela que ela se iniciou majoritariamente em nome de uma infância pobre e marginalizada, que vinha sendo historicamente violada em seus direitos humanos. A nosso ver, essa origem da luta pelos direitos da criança no Brasil pautou a militância de modo que por muito tempo o assunto ficou restrito à denúncia de violação de direitos e à responsabilização do Estado, afastando o debate da afirmação dos direitos (Arantes, 2009), o que valeria também para as crianças das elites.

Práticas assistenciais e de defesa de direitos conviveram no Brasil durante a redemocratização (e até hoje). Esse campo diverso de atores e instituições da área da infância encontrou no processo de redemocratização e na vigência da ANC (Assembleia Nacional Constituinte), de 1987 a 1988, oportunidade de incidir sobre as mudanças em pauta na legislação brasileira e colocaram a criança e o adolescente entre as prioridades ${ }^{1}$ do Estado na CF (Constituição Federal) de 1988; conquistando seu reconhecimento como sujeitos de direitos anos depois via ECA (Estatuto da Criança e do Adolescente).

A atuação dos grupos ou pessoas, ligadas ao governo ou à sociedade civil, em torno da ANC 87-88 demonstra a disputa do trato que a democracia brasileira, que estava sendo forjada naquele momento histórico, daria para a infância a partir dali. Como resultado da ANC 87-88, a CF priorizou as gerações mais novas na garantia de seus direitos sociais básicos. Todavia, não nos parece ter havido mudanças na posição da geração adulta perante a geração das crianças, visto que a CF coloca o Estado como agente provedor para a infância pobre ou marginalizada, enquanto a infância das classes médias e ricas continuou sendo considerada como problema das famílias nos espaços privados de socialização. A ideia de proteção da infância aparece simplificada e reduzida à ação do Estado em termos de uma 'proteção social' das crianças pobres. Por mais que tenha sido atuante a militância em torno dos direitos da criança, a CF acabou refletindo nossa tradição de evocar assistência para as crianças que são consideradas "desprotegidas" por suas famílias. Isso limitou de saída a compreensão do sentido amplo da proteção da infância que inclui necessariamente o dever do Estado, como representante do desejo da sociedade, de que todas as crianças sejam devidamente 
amparadas e cuidadas. Sobretudo, exclui-se deste cenário público a proteção como cuidado a ser dado a todas as crianças, inclusive aquelas de classes médias e ricas.

A defesa da criança enquanto sujeito detentor de direitos teve reconhecimento na legislação internacional a partir do final da década de 1970. A CNUDC (Convenção das Nações Unidas sobre os Direitos da Criança), aprovada na Assembleia Geral das Nações Unidas de 1989, reflete a Doutrina de Proteção Integral e formaliza a retórica dos direitos da criança. A ideia de proteção aqui tenta, entre outras mudanças, se distinguir do sistema tutelar e menorista de assistência para promover proteção e garantir simultaneamente o direito das crianças à participação, exercendo autonomia (Arantes, 2009).

Tal perspectiva foi efetivada na legislação brasileira com a ação dos movimentos de defesa dos direitos da criança e do adolescente na aprovação do ECA, em 1990, que a nosso ver não alterou profundamente a estrutura das mentalidades em relação à noção de infância e de proteção que vinha sendo difundida e executada no país.

Respeitando o princípio da diferença, o ECA reserva às crianças não apenas direitos da pessoa humana - direitos comuns a todos e que são aplicáveis inclusive a pessoas de gerações mais velhas. O ECA também reserva para as crianças direitos específicos que visam abarcar suas particularidades e, nesse sentido, se concretizam também como uma medida protetiva. A condição especial da criança de pessoa em desenvolvimento é a justificativa para direitos e proteção especiais. A nosso ver, o ECA realizou mudança positiva ao transformar a posição discriminatória do Estado em relação à criança pobre, cuja ação, agora não mais por beneficência ou caridade, mas por dever, deveria prover direitos de cidadania para essa população. Essa "virada" estendeu direitos especiais para todas as crianças, independente do seu status social e econômico, em que pese não ter rompido com a visão desenvolvimentista da infância. Da mesma forma, no que diz respeito à proteção, houve o ganho formal de, pela primeira vez, considerar a infância como uma única categoria.

Segundo algumas avaliações da defesa dos direitos da criança (Castro, 2012; Pinheiro, 2006), a criação do ECA, representou a tentativa no Brasil de compreender todas as pessoas de faixa etária específica sob o mesmo grupo geracional, o grupo da infância. Composto, portanto, pelas crianças pobres, ricas, socialmente "vulneráveis" ou não, estabelecendo equivalência legal entre elas sob o guarda-chuva de que todas elas são detentoras de direitos iguais, independente das diversas condições em que vivenciem suas infâncias. Tratou-se de uma tentativa de aproximar o 'menor' das outras crianças incluindo-os todos na geração da infância. Todavia, a aprovação do ECA por si só não mudou as condições materiais de vida, nem aboliu o preconceito social aos quais estão submetidas as 
crianças pobres. Além disso, a igualdade de direitos legais se fez em prol de um modelo "ideal" para a infância, sem se considerar como as peculiaridades das condições das crianças marginalizadas poderiam ser atendidas.

Durante a redemocratização do Brasil, a crise do Estado autoritário da ditadura militar permitiu a revalorização da ação dos indivíduos na vida pública por meio do reconhecimento dos direitos humanos que, apesar de resgatarem a cidadania e a liberdade no país, o fizeram dentro do processo de ocidentalização pelo qual passou a sociedade brasileira (Pinheiro, 2006). Consideramos que esse processo mais amplo de mudança na vida social e política do país teve impacto no campo da infância, haja vista a reprodução, no Brasil, do padrão europeu de direitos ditos universais - um processo que ocorreu com a adesão de alguns setores da sociedade à pauta dos direitos supostamente universais, apesar de não se ter enfrentado efetivamente os obstáculos na direção de diminuir as enormes desigualdades entre as diferentes infâncias no país.

\section{A Proteção Da Infância: De Qual Dever Se Trata Para A Geração Dos Adultos?}

Em 2015 celebramos vinte e cinco anos da criação do ECA. Vinte e cinco anos de existência no Brasil de legislação específica sobre a proteção integral e os direitos das crianças e dos adolescentes. Ao mesmo tempo, parecemos viver sob a égide da era dos direitos, na qual o discurso dos direitos individuais é difundido e as crianças tanto quanto os indivíduos de outras gerações - estão cientes do regime de direitos e como ele regula fortemente muitas dimensões da vida social, por exemplo: a relação entre cidadão e Estado; a relação entre consumidores, produtores e vendedores; a relação entre trabalhadores e empregadores; as relações entre pais, mães e filhos. A proteção da infância, enquanto um direito da criança, está, portanto, entrelaçada no discurso mais amplo dos direitos e na forma crescente como ele vem dominando a vida de todos nós. O regime de direitos, enquanto um regulador da vida social, vem sendo cada vez mais referência uníssona para resolvermos nossos problemas sociais, restando pouco espaço para pensarmos em outros denominadores que sejam referência para a ética na vida comum e na forma como nos relacionamos uns com outros; incluindo como nos relacionamos com as crianças.

Nesse sentido, a proteção da infância se tornou a norma que regula a relação dos adultos com as crianças, mas um sentido existencialmente denso de proteção ainda está por se fazer no país. Pelo que observamos na nossa realidade, a maioria das práticas comumente identificadas como protetoras reproduz a proteção como 
promoção de custódia e abrigamento para a criança, sobretudo para a criança pobre. Porém, sabemos que a proteção ganha densidade e relevo na vida das crianças de diferentes formas, a saber: proteção por meio ou não da ação governamental, com ou sem abrigamento institucional, com ou sem acesso a direitos especiais, com ou sem provisão por parte da família; além disso, sendo ou não nomeada como prática protetiva.

Além disso, estudos nacionais e internacionais no campo da infância (Arantes, 2009; Smith, 2012) têm ressaltado a tensão instaurada pelo regime de direitos da criança. Há o reconhecimento, por um lado, da condição de pessoa em desenvolvimento que evoca proteção; e por outro lado, há afirmação do sujeito de direitos que evoca autonomia. Embora os estudos defendam que essa tensão possa não ser necessariamente uma contradição, ela se concretiza como tal aos olhos de nossa sociedade - adultocêntrica e tutelar que demanda competências para conceder direitos. Essa tensão se expressa também em outros antagonismos envolvendo a infância como, por exemplo, o da menoridade versus capacidade, que foi muito presente em 2015 no país quando do debate público a respeito da proposta de redução da maioridade penal. Esses paradoxos envolvidos na forma como a infância é percebida refletem alguns dos "nós" que atravessam as relações intergeracionais entre adultos e crianças.

No que tange a nosso propósito com o presente trabalho, identificamos alguns problemas no imperativo da proteção da infância quando adotamos uma análise a partir de um enfoque geracional. Primeiro, identificamos um descompasso entre discriminações ainda presentes no regime de direitos e a exigência de que toda a geração da infância seja protegida. Não é, portanto, por acaso que as crianças que cometem infrações ainda relutantemente sejam consideradas, sentidas e pensadas como crianças. Este aspecto revela o tamanho do desafio ao problematizarmos a ideia de proteção que, a nosso ver, reflete a dificuldade das gerações mais velhas de se responsabilizarem em coletivo pela infância - por isso talvez o Estado continue sendo a autoridade evocada para proteger algumas crianças e não outras. Tal descompasso se expressa na terminologia da área, que até hoje nomeia a proteção da infância e defende os direitos da criança. Ou seja, desde a concepção dos direitos há uma aposta maior no sujeito detentor de direitos do que na garantia dos direitos comuns a uma unidade geracional.

Um segundo problema identificado é que o dever da proteção tal qual temos hoje, inserido dentro da retórica dos direitos, alterou pouco a ordem geracional vigente. Por mais que crianças sejam convidadas cada vez mais a exercer sua autonomia dando opinião e participando, elas ainda são pouco escutadas e satisfeitas em sua posição sobre os assuntos que interferem diretamente em sua vida. A perspectiva de 
que crianças precisam de orientação, tutela e proteção dos adultos faz com que a ação da infância ainda seja vista com um tom lúdico, como uma brincadeira permanente, e as grandes decisões da sua própria vida - ou de toda a geração da infância - sejam tocadas pela geração adulta, a qual ocupa o topo da hierarquia na ordem geracional e exerce poder e governo sobre a infância.

Para finalizar, indicamos um terceiro ponto problemático: o regime de direitos e o dever da proteção impactam as relações intergeracionais de modo que se configuram hoje como importantes reguladores das trocas entre adultos e crianças. Considerando que a afirmação de um direito requer ao mesmo tempo apontar uma responsabilidade de outrem para com o possuidor do direito (Enew, 1986), a afirmação do direito de proteção da infância apontou obrigatoriamente as gerações mais velhas e/ou o Estado como responsáveis por tal provisão. No que diz respeito ao debate geracional, a geração adulta se fixou como a promotora de proteção da infância. Ocorre que, o crescimento do discurso e da retórica dos direitos vem colocando a norma legal como reguladora das relações intergeracionais, substituindo as responsabilidades pessoais e coletivas que adultos têm para com crianças. A relação adulto-criança vem sendo amplamente pautada pelos direitos da segunda, e pelas conveniências dos primeiros tendo em vista não cometerem infrações. A nosso ver, isso normatiza a relação adulto-criança diminuindo espaço para a emergência de práticas que se sustentem mais na reciprocidade e menos no policiamento legal.

\section{Considerações finais}

Apontamos a necessidade de ampliarmos a compreensão do que são práticas protetoras, não as limitando ao trato público que é dado para a criança em conflito com a lei, ou para a criança em situação de rua, ou para a criança que foi submetida a algum tipo de exploração ou violência, ou para a criança que vive em condição de pobreza, ou para a criança institucionalizada, entre tantas outras crianças. É preciso ampliar a compreensão sobre proteção para não a restringir exclusivamente à assistência limitada que foi promovida historicamente para as crianças em situação de "vulnerabilidade" social. Por outro lado, precisamos ampliar a noção de proteção para que ela se inscreva nos sentidos mais amplos das obrigações que a geração de mais velhos tem em relação aos mais novos: o que é cuidar de uma geração? De todas as crianças que dela fazem parte? A ampliação da noção de proteção implicará, no Brasil, em uma profunda transformação de mentalidades na medida em que a reciprocidade exigida dos adultos demandará respostas no tocante à justiça e à igualdade de trato para toda uma geração. Como sujeito 
de direitos, a criança é aquele que deve ser cuidado e que deve participar na vida social. Sua proteção inclui todas as práticas de cuidado cotidiano e educação, inclusive com aquelas crianças que vivem uma infância "normal" - que não estão socialmente "vulneráveis" nem estão "desprotegidas" socialmente, por exemplo.

Tal mudança no debate conceitual do dever de proteção encontra certamente grandes barreiras para ser pensada no âmbito das políticas públicas, visto que tal campo se constituiu historicamente como espaço próprio da execução de práticas de proteção como forma de minorar as condições adversas da vida da infância pobre, marginalizada e/ou "vulnerável", ou ainda, de proteger a sociedade da visão da pobreza, da miséria e de supostos infratores em potencial. Ocorre, todavia, que enquanto a proteção da infância for sinônimo para a proteção da criança pobre, dificilmente operaremos transformações nas relações intergeracionais entre as gerações dos adultos e das crianças. O Estado continuará regulando uma infância pela via da assistência limitada e precária, enquanto outra passa ao largo dessa problemática. Isso dificulta o reconhecimento de certa unidade no grupo geracional da infância e se constitui como obstáculo para que a geração dos adultos assuma coletivamente responsabilidade por todas as crianças da mesma maneira.

\section{Referências}

Alanen, L. (2011). Generational Order. In J. Qvortrup, W. A. Corsaro, \& M. Honig (Orgs.), The Palgrave Handbook of Childhood Studies (pp. 159-176). Londres: Macmillan.

Alanen, L., \& Mayall, B. (2001). Conceptualizing child-adult relations. London, New York: Routledge.

Arantes, E. M. de M. (2009). Proteção integral à criança e ao adolescente: proteção versus autonomia? Psicologia Clínica, 21(2), 431-450. doi: 10.1590/S0103-56652009000200012

Brasil (2012). Constituição da República Federativa do Brasil: Texto constitucional promulgado em 5 de outubro de 1988, com as alterações adotadas pelas Emendas Constitucionais no $1 / 1992$ a 68/2011 pelo Decreto Legislativo oㅜ186/2008 e pelas Emendas Constitucionais de Revisão noos 1 a 6/1994. Brasília: Câmara dos Deputados, Edições Câmara.

Burman, E. (2008). Deconstructing developmental psychology. USA, Canada: Routledge.

Castro, L. R. de (2012). The Idea of development and the study of children in Brazil as a developing society. Psychology and developing societies, 24(2), 181-204. doi: $10.1177 / 097133361202400205$ 
Castro, L. R. de. (2013). O futuro da infância: os impasses nas relações intergeracionais e das crianças com seus pares. In L. R. de Castro (Autor), O futuro da infância e outros escritos ( $p p$. 37-84). Rio de Janeiro: 7Letras.

Enew, J. (1986). The sexual exploitation of children. Cambridge: Polity Press.

Faleiros, E. T. S. (2011). A criança e o adolescente. Objetos sem valor no Brasil Colônia e Império. In I. Rizzini, \& F. Pilotti (Orgs), A arte de governar crianças: A história das políticas sociais, da legislação e da assistência à infância no Brasil (pp. 203-222). São Paulo: Cortez.

Freitas, M. C. de (Org.) (2003). História Social da Infância no Brasil. São Paulo: Cortez.

Freixa, C., \& Leccardi, C. (2010). O conceito de geração nas teorias sobre juventude [Dossiê]. Revista Sociedade e Estado, 25(2), 185-204. doi: 10.1590/S0102-69922010000200003

Gillis, J. (2011). Transitions to Modernity. In J. Qvortrup, W. A. Corsaro, \& M. Honig (Orgs.), The Palgrave Handbook of Childhood Studies (pp. 114-126). Londres: Macmillan.

Goés, J. R., \& Florentino, M. (2013). Crianças escravas, crianças dos escravos. In: M. Del Priore (Org.), História das crianças no Brasil (pp. 177-191). São Paulo: Contexto.

Heywood, C. (2001). A history of childhood: Children and childhood in the west from Medieval to Modern times. Cambridge: Polity Press.

KjØrholt, A. T. (2013). Childhood as Social Investiments, Rights and the Valuing of Education [Special Issue]. Children \& Society, 27, 245-257. doi: 10.1111/chso. 12037

Kramer, S. (1982). História do atendimento à criança brasileira. In S. Kramer, A Política do Pré-escolar no Brasil: A arte do disfarce (pp. 49-91). Rio de Janeiro: Achiamé.

KuhImann Jr., M. (2010). Instituições pré-escolares assistencialistas no Brasil. In M. Kuhlmann Jr., Infância e Educação Infantil: Uma abordagem histórica (pp. 77-102). Porto Alegre: Mediação.

Lajolo, M. (2003). Infância de papel e tinta. In M. C. de Freitas (Org.), História social da infância no Brasil (pp. 229-250). São Paulo: Cortez.

Leite, M. L. M. (1991). O óbvio e o contraditório da Roda. In M. Del Priore (Org.), História da criança no Brasil (pp. 98-111). São Paulo: Contexto.

Mauad, A. M. (2013). A vida das crianças de elite durante o Império. In M. Del Priore (Org.), História das crianças no Brasil (pp. 137176). São Paulo: Contexto. 
Passetti, E. (2013). Crianças carentes e políticas públicas. In M. Del Priore (Org.), História das crianças no Brasil (pp. 347-375). São Paulo: Contexto.

Pinheiro, A. (2006). Criança e adolescentes no Brasil: Porque o abismo entre a lei e a realidade. Fortaleza: Universidade Federal do Ceará.

Priore, M. Del (Org.) (2013). História das crianças no Brasil. São Paulo: Contexto.

Qvortrup, J. (2011a). Nove teses sobre a "infância como um fenômeno social". Pro-Posições [Campinas], 22(1), 199-211, Jan/Abr. doi: 10.1590/S0103-73072011000100015

Qvortrup, J. (2011b). Childhood as a Structural Form. In J. Qvortrup, W. A. Corsaro, \& M. Honig (Orgs.), The Palgrave Handbook of Childhood Studies (pp. 21-33). Londres: Macmillan.

Rizzini, I., \& Rizzini, I. (2004). A institucionalização de crianças no Brasil: Percurso histórico e desafios do presente. Rio de janeiro \& São Paulo: Editora Loyola \& Editora PUC-Rio.

Smith, K. (2012). Producing governable subjects: images of childhood old and new. Childhood, 19(1), 24-37. doi: $10.1177 / 0907568211401434$

Smolka, A. L. B. (2002). Estatuto de sujeito, desenvolvimento humano e teorização sobre a criança. In M. C. Freitas, \& M. Kuhlmann Jr. (Orgs.), Os intelectuais na história da infância (pp. 99-129). São Paulo: Cortez.

Stearns, P. N. (2006). Childhood in world history. New York: Routledge.

Weller, W. (2010). A atualidade do conceito de gerações de Karl Mannheim [Dossiê]. Revista Sociedade e Estado, 25(2), Maio/Ago, 205-224. doi: 10.1590/S0102-69922010000200004

Weller, W., \& Motta, A. B. da (2010). Apresentação: a atualidade do conceito de gerações na pesquisa sociológica [Dossiê]. Revista Sociedade e Estado, 25(2), Maio/Ago, 175-184. doi: 10.1590/S0102-69922010000200002

\footnotetext{
Endereço para correspondência

Suzana Santos Libardi

Universidade Federal do Rio de J aneiro - UFRJ

Programa de Pós-graduação em Psicologia - UFRJ

Av. Pasteur, 250, Pavilhão Nilton Campos, Urca, CEP 22290-240, Caixa-postal 56056, Rio de Janeiro - RJ, Brasil

Endereço eletrônico: suzana.libardi@gmail.com

Lucia Rabello de Castro

Universidade Federal do Rio de J aneiro - UFRJ

Programa de Pós-graduação em Psicologia - UFRJ

Av. Pasteur, 250, Pavilhão Nilton Campos, Urca, CEP 22290-240, Caixa-postal 56056, Rio de Janeiro - RJ, Brasil

Endereço eletrônico: Ircastro@infolink.com.br
} 
Recebido em: 17/11/2016

Reformulado em: $17 / 12 / 2016$

Aceito em: 28/03/2017

\section{Notas}

* Possui doutorado (2016) em Psicologia pelo Programa de Pós-Graduação em Psicologia da Universidade Federal do Rio de Janeiro (PPGP-UFRJ), tendo sido bolsista CNPQ e bolsista FAPERJ "Nota 10". Em 2014 realizou doutorado sanduíche no exterior no Norwegian Centre for Child Research (NOSEB), em TrondheimNoruega, contando com apoio de bolsa da CAPES. É graduada em psicologia (Formação de Psicólogo) pela Universidade Federal de Pernambuco (UFPE).

** Possui doutorado (1988) em Psicologia pela Universidade de Londres, GrãBretanha. Atualmente é Professora Titular do Instituto de Psicologia da Universidade Federal do Rio de Janeiro, e professora do Programa de Pósgraduação em Psicologia desse Instituto. Membro Fundador do Núcleo Interdisciplinar de Pesquisa na Infância e Adolescência Contemporâneas NIPIAC/UFRJ, coordenadora geral desse Núcleo (1995-2010), e atual Coordenadora Científica. É editora chefe da DESidades-Revista Eletrônica de Divulgação Científica da Infância e Juventude.

${ }^{1}$ Por meio da formalização, na CF de 1988: da proteção à infância como um direito social provido pela assistência social (Artigos 203 e 223); do amparo às crianças e adolescentes carentes como um dos objetivos da assistência social (Artigo 223); da assunção legal de crianças, adolescentes e jovens como prioridade do Estado democrático brasileiro e alvo de proteção especial (Artigo 227), sendo expressa no respeito à condição peculiar de pessoa em desenvolvimento, principalmente quando da aplicação de medidas punitivas ao 'menor' (Artigo 227); entre outros direitos relativos à saúde, educação, lazer e segurança da criança (Brasil, 2012).

Este artigo de revista Estudos e Pesquisas em Psicologia é licenciado sob uma Licença Creative Commons Atribuição-Não Comercial 3.0 Não Adaptada. 